\title{
Perioperative course in 118 infants and children undergoing coarctation repair via a thoracotomy: A prospective, multicenter experience
}

\author{
Sarah Tabbutt, MD, PhD, ${ }^{a}$ Susan C. Nicolson, MD, ${ }^{a}$ Troy E. Dominguez, MD, ${ }^{a}$ Winfield Wells, MD, ${ }^{\text {b }}$ Carl L. Backer, MD, ${ }^{c}$ \\ James S. Tweddell, MD, ${ }^{d}$ Paula Bokesch, MD, ${ }^{e}$ and Mark Schreiner, $\mathrm{MD}^{\mathrm{a}}$
}

From the Children's Hospital of Philadelphia, ${ }^{a}$ Philadelphia, Pennsylvania; Los Angeles Children's Hospital, ${ }^{\mathrm{b}}$ Los Angeles, California; Children's Memorial Hospital, Chicago, Illinois; Children's Hospital of Wisconsin, ${ }^{\mathrm{d}}$ Milwaukee, Wisconsin; and Cleveland Clinic Foundation, ${ }^{\mathrm{e}}$ Cleveland, Ohio.

This study was sponsored by Baxter Healthcare Corporation, New Providence, NJ.

Received for publication Nov 27, 2007; revisions received May 7, 2008; accepted for publication June 15, 2008.

Address for reprints: Sarah Tabbutt, MD, $\mathrm{PhD}$, Medical Director, Cardiac Intensive Care Unit, The Cardiac Center, The Children's Hospital of Philadelphia, 34th St and Civic Center Blvd, Philadelphia, PA 19104 (E-mail: tabbutt@email.chop.edu).

J Thorac Cardiovasc Surg 2008;136:122936

\section{2-5223/\$34.00}

Copyright $\odot 2008$ by The American Association for Thoracic Surgery

doi:10.1016/j.jtcvs.2008.06.035
Objective: The hospital course for pediatric coarctation repair has not been described. We had 4 aims: (1) to determine the influence of age, anatomy, and type of repair on aortic crossclamp time, (2) to determine the impact of age or aortic crossclamp time on postoperative morbidity, (3) to describe current antihypertensive strategies, and (4) to describe antihypertensive medications at hospital discharge.

Methods: Data were obtained from a prospective randomized multicenter esmolol safety and efficacy trial. The study included patients who were scheduled for a coarctation repair receiving esmolol as their first-line antihypertensive medication in the operating room $(\mathrm{n}=118$; weight $\geq 2.5 \mathrm{~kg}$ and age $<6$ years $)$.

Results: (1) Patient age and type of coarctation did not affect the aortic crossclamp time. (2) Younger age, but not aortic crossclamp time, was associated with a significantly longer time to extubation and longer hospital length of stay. (3) A combination of esmolol and sodium nitroprusside (Nipride, Roche, Basel, Switzerland) provided excellent early blood pressure control. (4) At discharge, 64\% of patients were receiving antihypertensive medications. Older patients were more likely to be discharged with antihypertensive medication $(91 \%$ of patients aged $2-6$ years, $P<.0002)$.

Conclusion: The study describes a multi-institutional approach to the repair of isolated coarctation in infants and children. Patients repaired by end-to-end anastomosis had shorter aortic crossclamp time, younger patients had longer hospital length of stay, a majority of patients had sodium nitroprusside (Nipride) added to esmolol for early blood pressure control, and older patients were more likely to be discharged with antihypertensive medication.

0 urgical results are excellent for repair of coarctation of the aorta. ${ }^{1,2}$ Postoperative hypertension in these patients is a well-recognized phenomenon, and there are small cases series addressing the efficacy of antihypertensive medications. ${ }^{3-6}$ We utilized a multicenter esmolol safety and efficacy trial to obtain surgical and perioperative data in infants and children aged less than 6 years undergoing repair of coarctation of the aorta via a lateral thoracotomy. ${ }^{7}$ We had 4 specific aims from this multi-institutional pediatric population: (1) to determine the influence of age, anatomy, and type of repair on aortic crossclamp time, (2) to determine the impact of age or aortic crossclamp time on postoperative morbidity, (3) to describe current antihypertensive strategies and their ability to control blood pressure in the early postoperative period, and (4) to describe the frequency and type of antihypertensive medications at the time of hospital discharge.

\section{Materials and Methods}

Data were obtained from a prospective randomized multicenter (Appendix A) industry-sponsored esmolol safety and efficacy trial and a physician investigator-initiated substudy. ${ }^{7}$ The primary study was Food and Drug Administration approved and monitored, in addition to being approved by the individual institutions' institutional review boards. The patient population 


\section{Abbreviations and Acronyms}

ACEI $=$ angiotensin-converting enzyme inhibitor

$\mathrm{CI}=$ confidence interval

$\mathrm{ICU}=$ intensive care unit

$\mathrm{OR}=$ odds ratio

$\mathrm{SBP}=$ systolic blood pressure

included infants and children who weighed more than $2.5 \mathrm{~kg}$, were aged less than 6 years, and were scheduled for a coarctation repair via a lateral thoracotomy between August of 2000 and November of 2002, whose parent or legal guardian signed informed consent. Exclusion criteria included hypoglycemia, sensitivity to betablockers, low resting heart rate, depressed ventricular function, and abnormal screening laboratory results (Appendix B). A total of 164 patients met inclusion criteria, and informed consent was obtained. The final inclusion criterion was hypertension requiring treatment (neonate, systolic blood pressure [SBP] $\geq 80 \mathrm{~mm} \mathrm{Hg}$; infant, $\mathrm{SBP} \geq 85 \mathrm{~mm} \mathrm{Hg}$; child, $\mathrm{SBP} \geq 95 \mathrm{~mm} \mathrm{Hg}$ ) within 30 minutes of crossclamp release. A total of 118 patients (72\%) met the SBP criteria within 30 minutes of crossclamp release and received as their first-line antihypertensive a blinded esmolol bolus $(125,250$, or 500 $\mu \mathrm{g} / \mathrm{kg}$ ) immediately followed by an esmolol infusion at the same dose per minute $(125,250$, or $500 \mu \mathrm{g} / \mathrm{kg} / \mathrm{min})$ for a minimum of 15 minutes while in the operating room. There was no placebo control. After 5 minutes, additional antihypertensive medications could be added. After 15 minutes, changes in antihypertensive strategies were at the discretion of the practitioners. The results of the esmolol safety and efficacy trial are described elsewhere. ${ }^{7}$

Data presented were prospectively collected during the trial and include patient demographics, mode of diagnosis, associated cardiac lesions, preoperative clinical status, preoperative blood pressure gradient, surgical data, postoperative blood pressure gradients, intensive care unit (ICU) course, and use of antihypertensive agents. Blood pressure and heart rate were recorded hourly in the ICU for the first 12 hours and every 2 hours for the subsequent 12 hours.

Data analysis proceeded in 4 discrete steps. (1) Descriptive statistics were generated for the entire sample, focusing on preoperative, operative, and postoperative factors. (2) The association between age and crossclamp time with postoperative continuous variables was assessed using the Spearman correlation coefficient given the skewed nature of the distributions. For comparisons between these 2 factors and dichotomous variables, the Wilcoxon rank-sum test was used. (3) Several separate logistic regression models were specified and tested to estimate the relationship of age and crossclamp time with postoperative morbidities. (4) Logistic regression modeling was additionally used to estimate the relationship among age, crossclamp time, and postoperative antihypertensive treatment with discharge with antihypertensive medication. All data were analyzed using SAS 9.1 (SAS Institute, Cary, NC).

\section{Results}

\section{Preoperative}

Patient demographics and associated anomalies are listed in Table 1 . The median age was 4.8 months (0-84 months).
Three patients $(2.5 \%)$ had previous cardiac surgery, all of which were coarctation repairs. Preoperative diagnostic imaging included echocardiogram in 114 patients (97\%) and magnetic resonance imaging in 20 patients $(17 \%)$. The ductus arteriosus was patent in 30 patients (26\%), but only 1 patient was receiving prostaglandins. Eight patients (7\%) were mechanically ventilated preoperatively. Preoperative laboratory values included a median blood urea nitrogen of $9 \mathrm{mg} / \mathrm{dL}$ (3-21 mg/dL), creatinine of $0.4 \mathrm{mg} / \mathrm{dL}(0.2-1.2 \mathrm{mg} / \mathrm{dL})$, and hemoglobin of $12 \mathrm{~g} / \mathrm{dL}(9-18.6 \mathrm{~g} / \mathrm{dL})$.

Right arm SBP obtained in the operating room before induction of anesthesia was $119 \pm 24 \mathrm{~mm} \mathrm{Hg}$, with the associated SBP gradient to the lower extremity of $33 \pm 23 \mathrm{~mm} \mathrm{Hg}$.

\section{Intraoperative}

Operative times are shown in Table 2. Intraoperative description of the type of coarctation by the surgeon was discrete $(\leq 10 \mathrm{~mm})$ in 82 patients $(69 \%)$ and long segment $(>10$ $\mathrm{mm})$ in 36 patients $(31 \%)$. There was no significant difference in crossclamp time between discrete (median 18 minutes, 8-61 minutes) and long segment (median 16 minutes, 6-30 minutes, $P=.19$ ) coarctation. The type of surgical repair described by the surgeon and associated crossclamp times are shown in Table 3. Aortic crossclamp times were significantly shorter for resection with end-to-end anastomosis ( $\mathrm{n}=107$, median 16 minutes, 6-31 minutes) compared with other repairs ( $\mathrm{n}=11$, median 28 minutes, 12-61 minutes, $P=.001)$. The length of aortic crossclamp time was not associated with patient age $(P=.73)$.

\section{Postoperative}

The postoperative course is outlined in Table 4. There was no mortality. Twenty-five percent of patients $(n=30)$ were extubated in the operating room. Blood transfusion was administered to 35 patients $(30 \%)$. The incidence of blood transfusion trended toward significance in younger patients (odds ratio [OR] $0.98,95 \%$ confidence interval [CI] $0.96-1.01, P=.06)$ and just reached significance for longer crossclamp time (OR 1.1, 95\% CI 1.0-1.14, $P=.046$ ). Chest radiograph revealed pleural effusions in 10 patients $(8 \%)$ and pneumothorax in 17 patients (14\%). At the time of discharge, the creatinine was $0.3 \mathrm{mg} / \mathrm{dL}$ (range $0.1-0.9 \mathrm{mg} / \mathrm{dL}$ ) and hemoglobin was $11 \mathrm{~g} / \mathrm{dL}$ (range 7.0-19.8 g/dL).

Younger age was associated with a longer time to extubation (Spearman correlation coefficient $-0.57, P<.001$ ) and longer hospital length of stay (Spearman correlation coefficient $-0.34, P<.001)$. There was no significant association between aortic crossclamp time and time to extubation or hospital length of stay.

SBP gradient (right arm to a lower extremity) obtained 24 hours after arrival to the ICU was $7 \pm 13 \mathrm{~mm} \mathrm{Hg}$, which was significantly lower compared with $33 \pm 23 \mathrm{~mm} \mathrm{Hg}$ in the operating room before induction of anesthesia $(P<.001)$. 
TABLE 1. Patient demographics and associated anomalies

\begin{tabular}{|c|c|c|c|c|}
\hline & $\leq \mathbf{3 0} \mathrm{d}$ & $>30 \mathrm{~d}$ and $<2 \mathrm{y}$ & $2-6 y$ & Overall \\
\hline $\mathrm{N}$ & 30 & 52 & 36 & 118 \\
\hline Age, mo (median, range) & $0.4(0-1)$ & $3.8(1-24)$ & $43(27-84)$ & $4.8(0-84)$ \\
\hline Weight, kg (median, range) & $3.6(2.6-4.9)$ & $5.8(2.8-14.6)$ & $16.5(10.7-26)$ & $6.4(2.6-26)$ \\
\hline Male $(n, \%)$ & $22(73)$ & $32(62)$ & $25(69)$ & $79(67)$ \\
\hline Congenital anomalies ( $\mathrm{n}, \%$ ) & $6(20)$ & $5(10)$ & $2(6)$ & $13(11)$ \\
\hline Bicuspid aortic valve (n, \%) & $17(57)$ & $31(60)$ & $19(53)$ & $67(57)$ \\
\hline Ventricular septal defect $(\mathrm{n}, \%)$ & $7(23)$ & $5(10)$ & $0(0)$ & $12(10)$ \\
\hline
\end{tabular}

\section{Antihypertensive Therapies}

After 15 minutes of esmolol in the operating room, the protocol allowed the routine use of antihypertensive medications at the discretion of the care team. Therefore, the choice of antihypertensive agent in the ICU was independent of the protocol, but many centers may have chosen to continue the blinded esmolol after reaching therapeutic goals. The frequency of esmolol and sodium nitroprusside (Nipride) use during the first 24 hours in the ICU with associated SBP is shown by age groups in Figure 1. All patients who arrived in the ICU were receiving esmolol, and 61 patients (59\%) were also receiving sodium nitroprusside (Nipride). The use of a combination of esmolol and sodium nitroprusside (Nipride) on arrival to the ICU was more common in older children ( $\leq 30$ days of age $27 \%$ [8/30]; $>30$ days and $<2$ years 54\% [28/52]; 2-6 years $69 \%$ [25/36]). The need for antihypertensive infusions during the first 24 postoperative hours increased with older age. This was true for the number of hours that patients were treated with esmolol $(n=118$; correlation coefficient $0.38 ; P<.001$ ), hours treated with sodium nitroprusside (Nipride) $(\mathrm{n}=71$, correlation coefficient $0.33, P=.005)$ or hours treated with either esmolol or sodium nitroprusside (Nipride) ( $\mathrm{n}=118$, correlation coefficient $0.49, P<.001$ ). During the first 24 hours in the ICU, both infusions were gradually reduced and intermittent antihypertensive medications (both intravenous and oral) were introduced. At the end of the first 24 hours, 43 patients (36\%) were receiving esmolol and 28 patients $(24 \%)$ were receiving sodium nitroprusside (Nipride). This strategy provided excellent blood pressure control (Figure 1). Mean SBP during the first 24 hours was $83 \pm 3 \mathrm{~mm} \mathrm{Hg}$ for 30 days of age or less, $103 \pm 5 \mathrm{~mm} \mathrm{Hg}$ for more than 30 days and less than 2 years, and $116 \pm 3 \mathrm{~mm} \mathrm{Hg}$ for 2 to 6 years. The median duration of esmolol and sodium nitroprusside (Nipride) use after arrival in the ICU was 19.9 hours (0.380.7 hours) and 18.7 hours (0.4-99.8 hours), respectively. The median maximum dose of esmolol was $521 \mu \mathrm{g} / \mathrm{kg} / \mathrm{min}$ $(125-9333 \mu \mathrm{g} / \mathrm{kg} / \mathrm{min})$, and the median maximum dose of sodium nitroprusside (Nipride) was $3 \mu \mathrm{g} / \mathrm{kg} / \mathrm{min}(0.5-8 \mu \mathrm{g} / \mathrm{kg} /$ $\mathrm{min})$. There was a trend toward a higher maximum esmolol dose per unit body weight $(\mathrm{mg} / \mathrm{kg} / \mathrm{min})$ in older patients (Spearman correlation coefficient $0.17, P=.07$ ).

The initiation of intermittent antihypertensive medications was more common in the older patients (Figure 2). These agents were grouped into the following categories: (1) betablockers (atenolol, labetolol, and propranolol); (2) angiotension-converting enzyme inhibitor (enalaprilat, enalapril, and captopril); (3) calcium channel blockers (nicardipine and nifedipine); (4) alpha agents and vasodilators (phenoxybenzamine, clonidine, and hydralazine). Seventy-five patients (64\%) were discharged with antihypertensive medications including 14 patients (12\%) with a beta-blocker, 46 patients $(39 \%)$ with an angiotensin-converting enzyme inhibitor (ACEI), and 10 patients (8.5\%) with a combination of betablocker and ACEI. Breakdown by age is shown in Table 5 . Older patients were more likely to be discharged with antihypertensive medication (OR 1.1, 95\% CI 1.03-1.1, $P<.0002)$. Neither the maximum esmolol nor sodium nitroprusside (Nipride) dose was associated with the need for discharge on antihypertensive medication. However, patients requiring both esmolol and sodium nitroprusside (Nipride) infusions rather than a single infusion were more likely to be discharged with antihypertensive medication (OR 6.8; 95\% CI 3.0-15.7; $P<.001)$.

TABLE 2. Operative times for all patients

\begin{tabular}{|c|c|c|c|c|}
\hline & $\leq \mathbf{3 0} \mathrm{d}$ & $>30 \mathrm{~d}$ and $<2 \mathrm{y}$ & $2-6 y$ & Overall \\
\hline $\mathrm{N}$ & 30 & 52 & 36 & 118 \\
\hline Duration of anesthesia, $\mathrm{h}$ (median, range) & $2.3(1.6-5.8)$ & $2.8(1.7-5.6)$ & $3.1(1.6-5.8)$ & $2.8(1.6-5.8)$ \\
\hline Duration of surgery, ${ }^{a} \mathrm{~h}$ (median, range) & $1.2(0.8-4)$ & $1.6(0.8-4)$ & $1.8(0.8-4.5)$ & $1.6(0.8-4.5)$ \\
\hline Aortic crossclamp, min (median, range) & $16.0(10-61)$ & $16.5(9-31)$ & $17.0(6-31)$ & $16.5(6-61)$ \\
\hline
\end{tabular}

\footnotetext{
${ }^{\mathrm{a}}$ Incision to dressing.
} 
TABLE 3. Type of repair and associated aortic crossclamp times

\begin{tabular}{|c|c|c|c|c|}
\hline Type of repair & $\leq \mathbf{3 0} \mathrm{d}$ & $>30 \mathrm{~d}$ and $<2 \mathrm{y}$ & $2-6 y$ & Overall \\
\hline $\mathrm{n}$ & 30 & 52 & 36 & 118 \\
\hline \multicolumn{5}{|l|}{ Resection, end to end } \\
\hline $\mathrm{n}(\%)$ & $26(87)$ & $49(94)$ & $32(89)$ & $107(91)$ \\
\hline crossclamp time, min (median, range) & $16(10-29)$ & $16(9-31)$ & $17(6-29)$ & $16(6-31)$ \\
\hline \multicolumn{5}{|l|}{ Resection, end to side } \\
\hline $\mathrm{n}(\%)$ & $0(0)$ & $0(0)$ & $1(3)$ & $1(1)$ \\
\hline crossclamp time, $\min$ & - & - & 28 & 28 \\
\hline \multicolumn{5}{|l|}{ Patch augmentation } \\
\hline $\mathrm{n}(\%)$ & $0(0)$ & $1(2)$ & $3(8)$ & $4(3)$ \\
\hline crossclamp time, min (median, range) & - & 12 & $19(16-31)$ & $18(12-31)$ \\
\hline \multicolumn{5}{|l|}{ Subclavian flap } \\
\hline $\mathrm{n}(\%)$ & $1(3)$ & $2(4)$ & $0(0)$ & $3(3)$ \\
\hline crossclamp time, min (median, range) & 28 & $29(28-31)$ & - & $28(28-31)$ \\
\hline \multicolumn{5}{|l|}{ Reverse subclavian flap } \\
\hline $\mathrm{n}(\%)$ & $3(10)$ & $0(0)$ & $0(0)$ & $3(3)$ \\
\hline crossclamp time, min (median, range) & $30(23-61)$ & - & - & $30(23-61)$ \\
\hline
\end{tabular}

\section{Discussion}

Surgical outcomes for repair of coarctation of the aorta are excellent, as recently reported for both infants ${ }^{2,8}$ and adolescents. ${ }^{9}$ There is limited information on the perioperative course and current strategies to control hypertension in the pediatric population. The establishment of a prospective esmolol trial provided a unique opportunity to look in a multicenter fashion at current approaches to coarctation repair, perioperative course, and antihypertensive therapies in children less than 6 years of age. Four aims were addressed in this physician investigator-initiated substudy: (1) to determine the influence of age, anatomy, and type of repair on aortic crossclamp time; (2) to determine the impact of age or aortic crossclamp time on postoperative morbidity or hospital length of stay; (3) to describe current antihypertensive strategies and their ability to control blood pressure in the early postoperative period; and (4) to describe the frequency and type of antihypertensive medications at the time of hospital discharge.

Recently reported surgical approaches via a thoracotomy vary from subclavian flap approach ${ }^{8}$ to end-to-end or extended end-to-end anastomosis. ${ }^{1,2,10}$ In this multi-institutional population $(n=107), 91 \%$ of patients had an end-to-end anastomosis with the coarctation described by the surgeon as discrete $(<10 \mathrm{~mm})$ in $69 \%$ of patients. Aortic crossclamp time was not significantly influenced by patient age or type of coarctation (discrete vs long-segment). The aortic crossclamp time was significantly shorter for the end-to-end anastomosis compared with other types of surgical repairs $(P<.001)$.

Blood pressure was well controlled in the postoperative period. The mean blood pressure gradient was reduced from $34 \pm 22 \mathrm{~mm} \mathrm{Hg}$ to $7 \pm 14 \mathrm{~mm} \mathrm{Hg}$, similar to previously reported values. ${ }^{10}$ Thirty percent of patients underwent endotracheal extubation in the operating room, with a median time to extubation of 7 hours ( $0-352$ hours). The median time to hospital discharge was 4 days (2-80 days). Younger age was associated with a longer time to extubation $(P<.001)$ and longer hospital length of stay $(P<.001)$. Aortic crossclamp time was not associated with time to extubation or hospital length of stay.

Postoperative hypertension is well recognized, ${ }^{11-13}$ even in neonates. ${ }^{14}$ This has been attributed to abnormal elastic properties as demonstrated by echocardiography both before and after repair in newborns ${ }^{15}$ and abnormalities in autonomic function, including diminished heart rate variability. ${ }^{12,14}$ It is uncertain whether these physiologies relate to the observed late hypertension. ${ }^{16,17}$

TABLE 4. Postoperative course

\begin{tabular}{|c|c|c|c|c|}
\hline & $\leq \mathbf{3 0} \mathrm{d}$ & $>30 \mathrm{~d}$ and $<2 \mathrm{y}$ & 2-6 y & Overall \\
\hline $\mathrm{n}$ & 29 & 52 & 33 & 114 \\
\hline Hours to extubation ${ }^{\text {a }}$ (median, range) & $21(0-95)$ & $5(0-352)$ & $1(0-26)$ & $7(0-352$ \\
\hline Days to ICU discharge (median, range) & $3(1-11)$ & $2(1-16)$ & $2(1-4)$ & $2(1-16)$ \\
\hline Days to hospital discharge (median, range) & $5(2-17)$ & $4(2-80)$ & $4(2-8)$ & $4(2-80)$ \\
\hline
\end{tabular}

$I C U$, Intensive care unit. ${ }^{a}$ Time from dressing placement at end of surgery. 

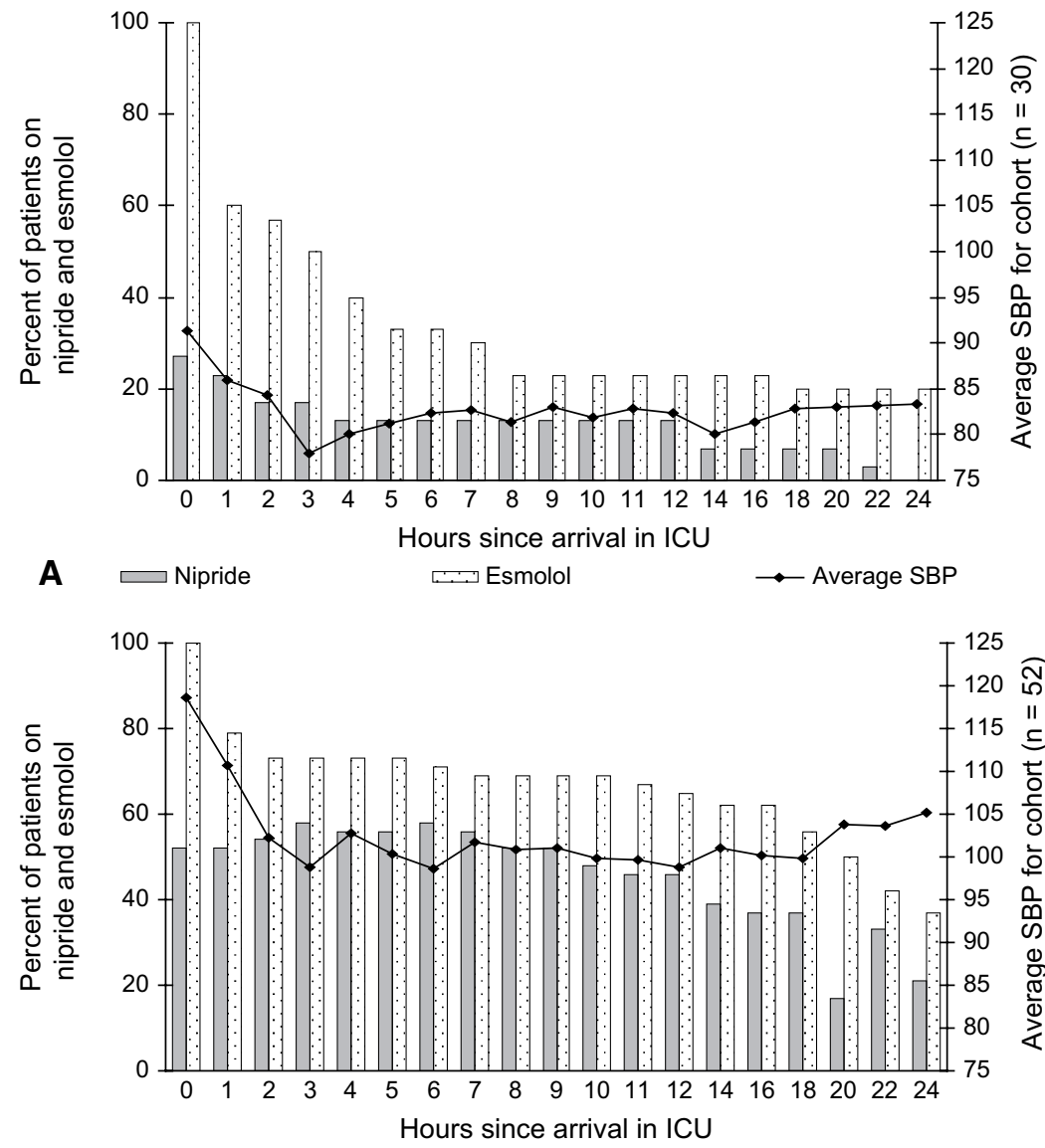

B

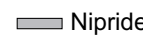

$\because$ Esmolol

$\multimap$ Average SBP

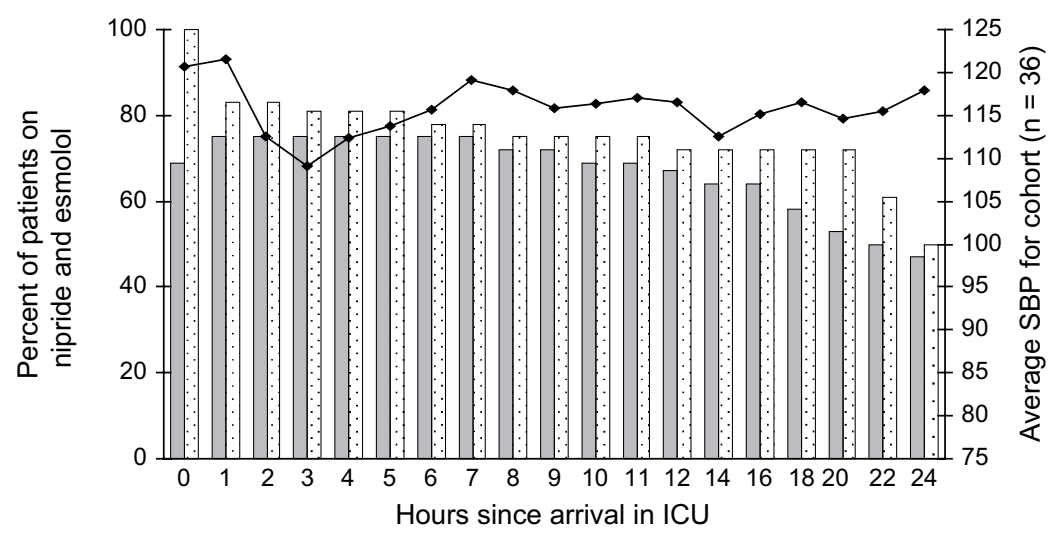

C

$\varpi$ Nipride

Æ... Esmolol

$\rightarrow$ Average SBP
Figure 1. Percentage of patients receiving esmoIol and sodium nitroprusside (Nipride, Basel, Switzerland) infusions (left axis) during the first 24 hours after arrival in the ICU is shown with mean SBP for the age group cohort (right axis). A, Patients aged less than $\mathbf{3 0}$ days, $\mathbf{n}=\mathbf{3 0}$. B, Patients aged between 30 days and 2 years, $n=52$. C, Patients aged between 2 and 6 years, $n=36$. $I C U$, Intensive care unit; $S B P$, systolic blood pressure.
Therapies for immediate postoperative hypertension are varied with a small case series in the literature. ${ }^{3-6}$ This patient population provides a multi-institutional overview of the current antihypertensive strategies used after surgical coarctation repair in infants and children in North America, with a bias toward the use of esmolol. All patients arrived in the ICU receiving esmolol, and $59 \%$ of patients were also receiving sodium nitroprusside (Nipride). The use of antihypertensive medications increased with patient age.
At the time of discharge ( $5 \pm 7$ days), $64 \%$ of patients were receiving antihypertension medications. Neither the maximum esmolol nor sodium nitroprusside (Nipride) dose was associated with the need for discharge with antihypertensive medication. However, patients requiring both esmolol and sodium nitroprusside (Nipride) infusions rather than a single infusion were more likely to be discharged with antihypertensive medication. Older patients were more likely to require medications $(P<.0002)$. 


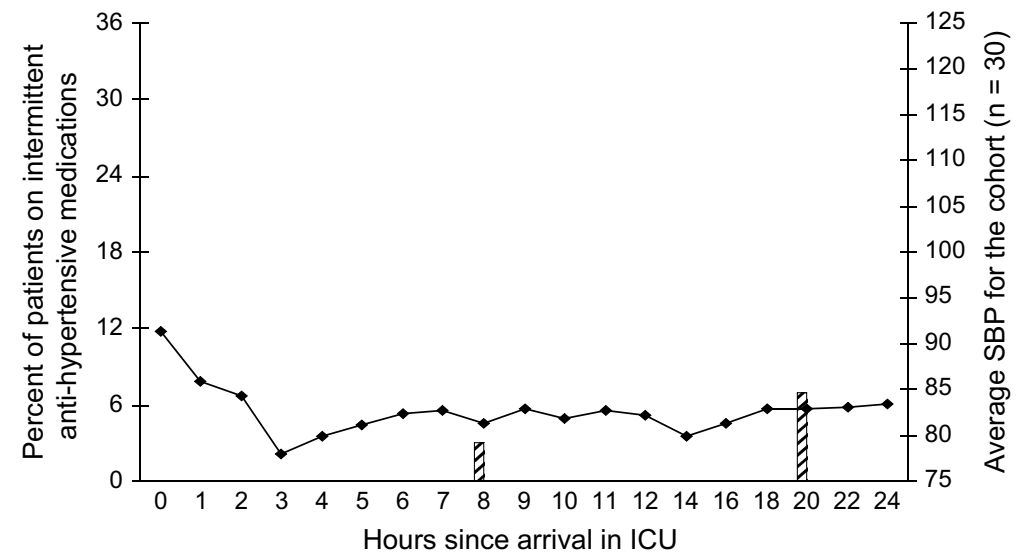

A
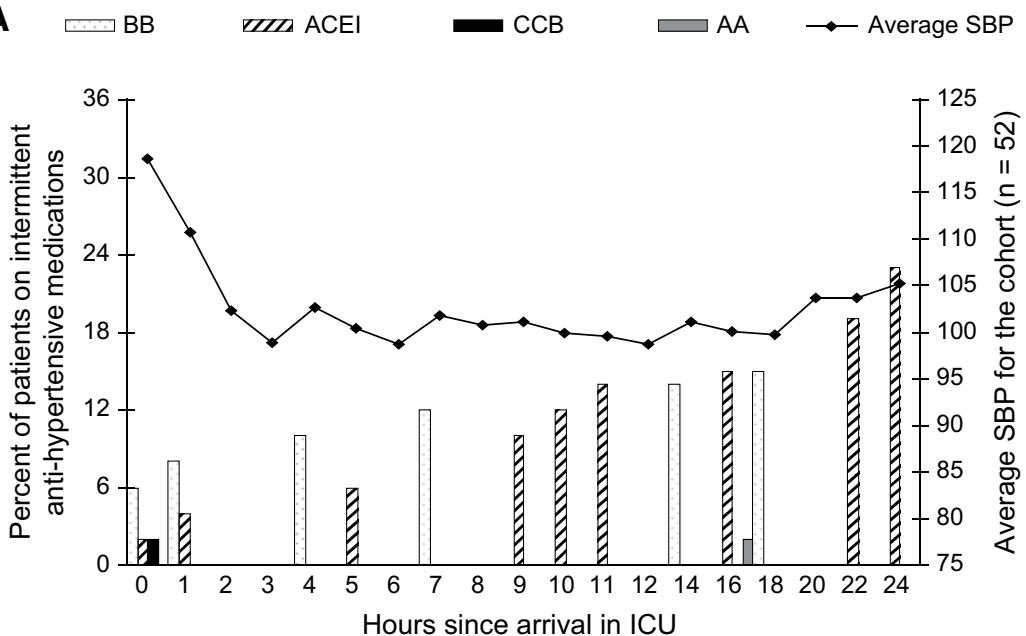

B $\square \mathrm{BB} \quad \mathrm{CCB} \mathrm{ACEI} \quad \mathrm{CA} \longrightarrow$ Average SBP

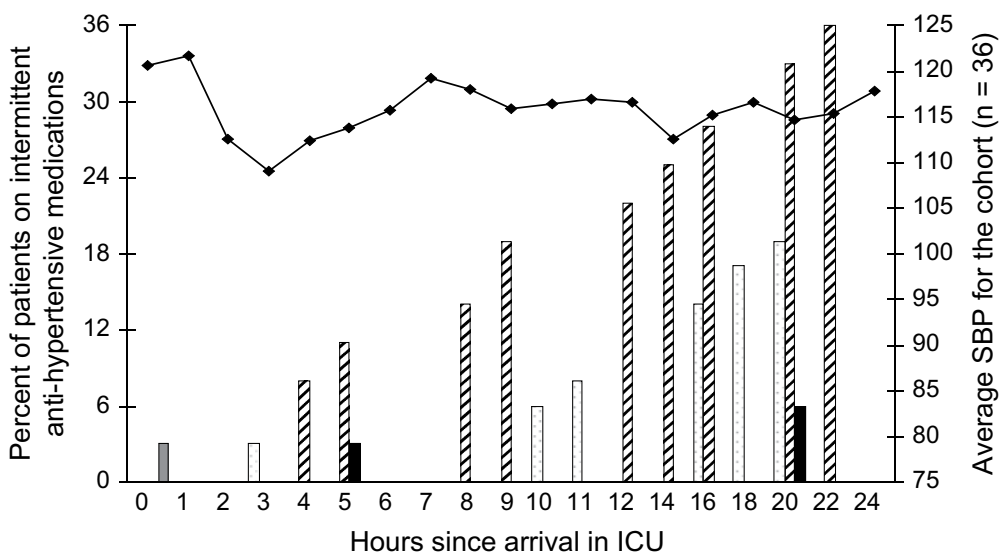

C EmA ACE
एAA
Figure 2. Percentage of patients receiving intermittent antihypertensive medications (left axis) during the first $\mathbf{2 4}$ hours after arrival in the ICU is shown with mean SBP for the age group cohort (right axis). Medications were categorized as beta-blockers (atenolol, labetolol, and proprano(ol); angiotension-converting enzyme inhibitors (enalaprilat, enalapril, and captopril); calcium channel blockers (nicardipine and nifedipine); and alpha agents and vasodilators (phenoxybenzamine, clonidine, hydralazine). A, Patients aged less than 30 days, $\mathbf{n}=\mathbf{3 0}$. B, Patients aged between 30 days and 2 years, $n=52$. C, Patients aged between 2 and 6 years, $n=36$. ICU, Intensive care unit; $B B$, beta-blocker; $A C E l$, angiotensinconverting enzyme; $C C B$, calcium channel blocker; $A A$, alpha agent and vasodilator; $S B P$, systolic blood pressure.
Only $17 \%$ of infants (5/30) aged 30 days or less were discharged with antihypertensive medications, with all but 1 patient receiving an ACEI. However, 92\% of children (33/36) aged 2 to 6 years were discharged with antihypertensive medications, with half receiving ACEI and $40 \%$ receiving a beta-blocker or combination of beta-blocker and ACEI.

\section{Study Limitations}

This study included only patients who gave informed consent, met blood pressure criteria, and received intraoperative esmolol. Patients described in this study were treated at institutions that are likely biased toward the use of esmolol. The use of blinded esmolol may likely have influenced the early choice of antihypertensive medications. 


\section{TABLE 5. Antihypertensive medications at hospital discharge}

\begin{tabular}{lccc}
\hline & $\mathbf{3 0} \mathbf{d}$ & $\mathbf{> 3 0}$ d and $<\mathbf{2 ~ y ~}$ & $\mathbf{2 - 6} \mathbf{~}$ \\
\hline $\mathrm{N}$ & 30 & 52 & 36 \\
$\begin{array}{l}\text { Discharged with } \\
\quad \text { antihypertensive medication }\end{array}$ & $5(17 \%)$ & $37(71 \%)$ & $33(92 \%)$ \\
$\begin{array}{l}\text { Discharged with beta-blocker } \\
\text { Discharged with ACEI }\end{array}$ & 0 & $5(14 \%)$ & $9(27 \%)$ \\
$\begin{array}{l}\text { Discharged with } \\
\quad \text { beta-blocker and ACEI }\end{array}$ & 0 & $6(16 \%)$ & $4(12 \%)$ \\
Discharged with other & $1(20 \%)$ & $1(2 \%)$ & $3(9 \%)$ \\
\hline
\end{tabular}

ACEI, Angiotension-converting enzyme inhibitor.

\section{Conclusions}

This is the first study to describe a multi-institutional approach to surgical repair of coarctation of the aorta in pediatrics. There was no mortality, neurologic complications, or clinically significant mesenteric ischemia. (1) Patient age and type of coarctation did not affect aortic crossclamp time, but those undergoing a resection and end-to-end anastomosis $(91 \%)$ had a significantly shorter crossclamp time. (2) Younger patient age, but not aortic crossclamp time, was associated with a significantly longer time to extubation and longer hospital length of stay. (3) All patients arrived in the ICU receiving esmolol, and an additional $59 \%$ of patients were also receiving sodium nitroprusside (Nipride) (69\% of those aged 2-6 years). (4) At the time of discharge, $64 \%$ of patients were receiving antihypertensive medications, with angiotension-converting enzyme inhibitors and betablockers most commonly used. Older patients were significantly more likely to be discharged with antihypertensive medication (91\% of patients aged 2-6 years).

The authors thank Michelle DeSilvio, PhD, and Xuemei Zhang, MS, for assistance with the statistical analyses.

\section{References}

1. Thomson JDR, Mulpur A, Guerrero R, Nagy Z, Gibbs JL, Watterson KG. Outcome after extended arch repair for aortic coarctation. Heart. 2006;92:90-4.

\section{Appendix A. Participating Centers}

United States: Children's Hospital of Philadelphia, Philadelphia, PA, Sarah Tabbutt, MD, PhD, Susan Nicolson, MD; Los Angeles Children's Hospital, Los Angeles, CA, Winfield Wells, MD; Cleveland Clinic Foundation, Cleveland, OH, Paula Bokesch, MD; Children's Hospital of Wisconsin, Milwaukee, WI, James Tweddell, MD; Children's Hospital Boston, Boston, MA, Francis McGowan, MD; Children's
2. Fesseha AK, Eidem BW, Dibardino DJ, Cron SG, McKenzie ED, Fraser CD, et al. Neonates with aortic coarctation and cardiogenic shock: presentation and outcomes. Ann Thorac Surg. 2005;79:1650-5.

3. Nakagawa TA, Sartori SC, Morris A, Schneider DS. Intravenous nicardipine for treatment of postcoarctectomy hypertension in children. Pediatr Cardiol. 2004;25:26-30.

4. Rouine-Rapp K, Mello DM, Hanley FL, Reddy VM, Soifer S. Effect of enalaprilat on postoperative hypertension after surgical repair of coarctation of the aorta. Pediatr Crit Care. 2003;4:327-32.

5. Giddings SS, Rocchini AP, Beekman R, Szpunar CA, Moorehead C, Behrendt D, et al. Therapeutic effect of propranolol on paradoxical hypertension after repair of coarctation of the aorta. $N$ Engl J Med. 1985; 213:1224-8

6. Leenen FH, Balfe JA, Pelech AN, Barker GA, Balfe JW, Olley PM. Postoperative hypertension after repair of coarctation of aorta in children: protective effect of propranolol. Am Heart J. 1987;113:1164-73.

7. Tabbutt S, Nicolson SC, Adamson P, Zhang X, Hoffman ML, Wells W, et al. The safety, efficacy and pharmacokinetics of esmolol for directed at blood pressure control immediately after repair of coarctation of the aorta in infants and children: a multicenter, double-blind, randomized trial. J Thorac Cardiovasc Surg. 2008;136:321-8.

8. Pandey R, Jackson M, Ajab S, Gladman G, Pozzi M. Subclavian flap repair: review of 399 patients at median follow-up of fourteen years. Ann Thorac Surg. 2006;81:1420-8.

9. Carr JA, Amato JJ, Higgins RSD. Long-term results of surgical coarctectomy in the adolescent and young adult with 18-year follow-up. Ann Thorac Surg. 2005;79:1950-6.

10. Walhout RJ, Lekkerkerker JC, Oron GH, Bennink GBWE, Meijboom EJ. Comparison of surgical repair with balloon angioplasty for native coarctation in patients from 3 months to 16 years of age. Eur J Cardiothorac Surg. 2004;25:722-7.

11. Rocchini AP, Rosenthal A, Barger AC, Castaneda AR, Nadas AS. Pathogenesis of paradoxical hypertension after coarctation resection. Circulation. 1976;54:382-7.

12. Beekman RH, Katz BP, Moorehead-Steffens C, Rocchini AP. Altered baroreceptor function in children with systolic hypertension after coarctation repair. Am J Cardiol. 1983;52:112-7.

13. Benedict CR, Grahame-Smith DG, Fisher A. Changes in plasma catecholamines and dopamine beta-hydroxylase after corrective surgery for coarctation of the aorta. Circulation. 1978;57:598-602.

14. Polson JW, McCallion N, Waki H, Thorne G, Tooley MA, Paton JFR, et al. Evidence for cardiovascular autonomic dysfunction in neonates with coarctation of the aorta. Circulation. 2006;113:2844-50.

15. Vogt M, Kuhn A, Baumgartner D, Baumgartner C, Busch R, Kostolmy M, et al. Impaired elastic properties of the ascending aorta in newborns before and early after successful coarctation repair. Proof of a systemic vascular disease of the prestenotic arteries? Circulation. 2005;111:3269-73.

16. Ou P, Bonnet D, Auriacombe L, Pedroni E, Balleux F, Sidi D, et al. Late systemic hypertension and aortic arch geometry after successful repair of coarctation of the aorta. Eur Heart J. 2004;25:1853-9.

17. Instebo A, Norgard G, Helgheim V, Roksnd OD, Segadal L, Greve G. Exercise capacity in young adults with hypertension and systolic blood pressure difference between right arm and leg after repair of coarctation of the aorta. Eur J Appl Physiol. 2004;93:116-23.

Memorial Hospital, Chicago, IL, Carl Backer, MD; TX Children's Hospital, Houston, TX, Steven Stayer, MD; Columbus Children's Hospital, Columbus, OH, Jill Fitch, MD; Children's Hospital of Cincinnati, Cincinnati, OH, David Nelson, MD, PhD; University of MI, Ann Arbor, Mich, Thomas Kulik, MD; San Diego Children's Hospital, San Diego, CA, David Bichell, MD; Hope Children's Hospital, Oak Lawn, 
IL, Joanne Starr, MD; Duke University, Durham, NC, Scott Schulman, MD; Montefiore Medical Center, Bronx, NY, Gregory Crooke, MD; Denver Children's Hospital, Denver, CO, Dunbar Ivy, MD; Children's National Medical Center, Washington DC, Eric Quivers, MD; University of Iowa,

\section{Appendix B. Exclusion Criteria}

1. The patient has an awake resting heart rate: less than $120 \mathrm{bpm}$ (neonate, $\leq 28$ days), less than $90 \mathrm{bpm}$ (infant, $>28$ days and $<1$ year), or less than $70 \mathrm{bpm}$ (child, $\geq 1$ year and $<6$ years).

2. The patient has had reactive airway disease requiring any form of therapy within the past week or requiring hospitalization within the past year.

3. The patient has a known sensitivity to beta-blockers as determined by the investigator.

4. The patient is hypoglycemic (glucose $<60 \mathrm{mg} / \mathrm{dL}$ ) on their screening laboratory results.

5. The patient has participated in a randomized study or has been exposed to an experimental drug within 28 days before enrollment in this study.

6. The patient has concomitant complex congenital heart disease requiring cardiopulmonary bypass. Hemodynamically insignificant disease (eg, atrial septal
Iowa City, IA, Javier Campos, MD; Children's Hospital of Pittsburg, Pittsburg, PA, Gerard Boyle, MD.

Canada: British Columbia Children's Hospital, Vancouver BC, Suvro Sett, MD; Hospital for Sick Children, Toronto, Glen Van Arsdell, MD.

defect, ventricular septal defect, or mild pulmonary stenosis) is not reason for exclusion.

7. The patient has had an episode of shock, acidosis, or depressed left ventricular function within 48 hours of surgery, or is receiving dopamine $(>5 \mu \mathrm{g} / \mathrm{kg} / \mathrm{min})$ for low cardiac output.

8. The patient's screening laboratory results include the following: hemoglobin $<9 \mathrm{~g} / \mathrm{dL}$, platelet count $<$ $100,000 / \mu \mathrm{L}$, white blood cell count $<1000 / \mu \mathrm{L}$, creatinine or blood urea nitrogen $>1.5$ times the upper limit of normal for age, alanine or aspartate aminotransferase $>2$ times the upper limit of normal for age.

9. The patient was previously treated under this protocol.

10. The patient is already receiving a beta-blocker or other long-acting antihypertensive. 